\title{
Mitral valve bioprosthesis is safer than mechanical mitral prosthesis in young women
}

\author{
hamdy singab ${ }^{1}$ and Gamal Sami ${ }^{2}$ \\ ${ }^{1}$ Ain Shams University Faculty of Medicine \\ ${ }^{2}$ Nasser Institute for Research and Treatment
}

June 10, 2020

\begin{abstract}
Background and aim: The ultimate goal of mitral valve surgery in young women is to extend life expectancy and improve quality of life. Mitral valve replacement (MVR) prosthesis in middle-aged women is a difficult choice between the lifelong anticoagulation by mechanical prosthesis versus the limited long-term durability of bioprosthesis. The current trend towards reducing women's age for selecting bioprosthesis over mechanical prosthesis leads to a dilemma for younger women decision making.1,2 The aim of this study was to compare the safety and freedom from complications in pregnancy and survival rate after mitral valve bioprosthesis versus mechanical prosthesis in young women for whom mitral valve repair is not feasible or unsuitable. Methods: This single-center non randomized prospective propensity-matched comparative study included all female patients undergoing MVR at our center from January 2010 to February 2020. Results: In total, 355 patients underwent MVR at our center, of whom 174 received a bioprosthesis and 181 received a mechanical prosthesis. The use of anticoagulation among young women with mechanical prosthesis was associated with a remarkable risk of postoperative bleeding, abortion, and increased frequency of pregnancy-related complications $(p<0.0001)$. In contrast, there was a considerable survival benefit for those who received bioprosthesis $(\mathrm{p}=0.0001)$. Conclusions: Our data confirm that the use of mitral bioprosthesis in young women who desire to become pregnant is safe, reduces complications, and increases survival.
\end{abstract}

\section{Mitral valve bioprosthesis is safer than mechanical mitral prosthesis in young women}

Hamdy Singab1,*, PhD; Gamal Sami2, 3, PhD

1 Department of Cardiovascular and thoracic Surgery, Faculty of medicine, Ain Shams University, Cairo, Egypt

2 Nasser Institute for Research and Treatment, Cardiothoracic Surgery Cairo, Egypt

3 Department of Cardiovascular and thoracic Surgery, Faculty of medicine, Ain Shams University, Cairo, Egypt

\section{*Corresponding author:}

Department of Cardiac Surgery,

Faculty of medicine, Ain Shams University,

Abbasia square, Cairo, Egypt,

P.O. Box 11517, Cairo, Egypt

Telephone: 00201001008859

Fax: 002022604465 
E-mail: hamdi_singab@hotmail.com

drhamdy-ahmed@med.asu.edu.eg

Running title: Mitral valve replacement prostheses

Funding: None

Abstract

\section{Background and aim:}

The ultimate goal of mitral valve surgery in young women is to extend life expectancy and improve quality of life. Mitral valve replacement (MVR) prosthesis in middle-aged women is a difficult choice between the lifelong anticoagulation by mechanical prosthesis versus the limited long-term durability of bioprosthesis. The current trend towards reducing women's age for selecting bioprosthesis over mechanical prosthesis leads to a dilemma for younger women decision making. 1,2

The aim of this study was to compare the safety and freedom from complications in pregnancy and survival rate after mitral valve bioprosthesis versus mechanical prosthesis in young women for whom mitral valve repair is not feasible or unsuitable.

\section{Methods:}

This single-center non randomized prospective propensity-matched comparative study included all female patients undergoing MVR at our center from January 2010 to February 2020.

\section{Results:}

In total, 355 patients underwent MVR at our center, of whom 174 received a bioprosthesis and 181 received a mechanical prosthesis. The use of anticoagulation among young women with mechanical prosthesis was associated with a remarkable risk of postoperative bleeding, abortion, and increased frequency of pregnancy-related complications $(\mathrm{p}<0.0001)$. In contrast, there was a considerable survival benefit for those who received bioprosthesis $(\mathrm{p}=0.0001)$.

\section{Conclusions :}

Our data confirm that the use of mitral bioprosthesis in young women who desire to become pregnant is safe, reduces complications, and increases survival.

Key words : cardiac valve prostheses, mitral valve replacement, biological valve, mechanical valve

\section{Introduction}

The ultimate goal of mitral valve surgery in young women is to extend life expectancy and improve and improve quality of life. Mitral valve replacement (MVR) prosthesis in middle-aged women is a difficult choice between the lifelong anticoagulation of mitral mechanical prosthesis (MMP) versus the limited longterm durability of mitral bioprosthesis (MBP). The current trend towards reducing women's age for selecting MBP over MMP leads to a dilemma for younger women decision making. [1,2] However, limited literature supports the use of MBP over MMP, and many surgeons and cardiologists recommend reducing women's age for MBP.[3 ]

The guidelines of the American College of Cardiology/American Heart Association advise using BMP for sinus rhythm in young women who choose this valve according to their lifestyle considerations, after having been comprehensively informed on the anticoagulation risk of MMP versus the necessity of future reoperation after MBP.[4] Several studies have reported that both MBP and MMP have equivalent effects on postoperative survival and quality of life in the middle-aged population. $[5,6]$ 
Young women, particularly those in child-bearing period, are concerned about MMP due to its bothering valve sounds, the need of repeated medical visits and blood tests, as well as the probability of anticoagulantrelated teratogenicity, thrombosis, and bleeding complications. [7]

The aim of this study was to compare the safety, freedom from complications during pregnancy, and the survival rate after MBP versus MMP in young women for whom mitral valve repair is not feasible or unsuitable.

\section{Materials and methods}

\section{Study design and participants}

This was a single-center, non-randomized, prospective, propensity-matched, comparative study registration of female patients who underwent MVR at the Cardiothoracic Department of Ain Shams University, Cairo, Egypt, from January 2010 to February 2020. Matched pairs based on identical or very similar propensity scores were compared in subsequent analyses. Logistic regression analysis based on explanatory variables was used for calculating the propensity score for each subject. Propensity score matching is an estimation method applied to situations, such as pregnancy, for which randomized clinical trials are unlikely to be performed.[8]

This study was approved by the local ethics committee and was conducted in accordance with the Helsinki Declaration. All patients provided written informed consent before the surgical procedures.

\section{Selection criteria}

We included all women patients undergoing MVR at our center from January 2010 to February 2020. We also included patients who underwent MVR with atrial fibrillation (AF) ablation and tricuspid valve repair or replacement. Age, sinus rhythm, and lifestyle were considered as a recommendation for MBP. Women who desired to become pregnant, for whom oral anticoagulants were contraindicated, and who showed poor anticoagulant compliance were also considered for MBP, even if they were $<60$ years old. Our exclusion criteria were infective endocarditis, prior cardiac operation, cardiogenic shock, emergency operation, and concomitant coronary artery bypass graft or aortic valve replacement. All patients with MBP received oral acetylsalicylic acid at $150 \mathrm{mg}$ daily only for the first 3-6months, while those with MMP +/- AF regularly received daily oral anticoagulants such as coumadin (warfarinß), Bristol-Myers Squibb, Egypt).

\section{Data collection}

Follow-up data were collected at our centre's outpatient clinic. The follow-up rate was $92 \%$ for the MBP group and $95 \%$ for the MMP group. Doctors and nurses in our research team did their best to reduce the number of patients lost to follow-up by maintaining telephone contact with the participants or their relatives at regular intervals or by using the National data death registration database through the participants' unique national ID for those who could not be contacted after multiple efforts.

For all patients, we collected basic preoperative sociodemographic and clinical data [age, body mass index, socioeconomic status, New York Heart Association (NYHA) classification, previous cardiological interventions, cardiovascular risk factors, comorbidities, European System for Cardiac Operative Risk Evaluation (EuroScore), echocardiography], and laboratory data. We also recorded the patients' preoperative and postoperative echocardiographic data, including ejection fraction, left ventricular end diastolic diameter $(\mathrm{mm})$, left ventricular end systolic diameter $(\mathrm{mm})$, left atrium $(\mathrm{mm})$, right atrium $(\mathrm{mm})$, mitral opening $(\mathrm{mm})$, and mitral valve pathologies; intra-operative transesophageal echocardiography (TEE) data, as well as TTE data at one week post-operation and upon clinical follow-up [9,10];relevant medical or surgical history; operative variables [surgical approach (conventional or minimally invasive), cross clamp time, bypass time, type and size of mitral prostheses, concomitant AF ablation, and tricuspid procedures]; and postoperative variables [ventilation time, intensive care unit (ICU) stay, hospital stay, pleural effusion, pericardial tamponade, wound infection, arrhythmia (atrio-ventricular (A-V) block-AF],pneumothorax, pneumonia, stroke, acute renal failure(ARF), temporary dialysis, neurological complication, pacemaker implantation, 30-day and 10-year cardiac 
and non-cardiac death].

Study outcomes

Statistical analyses

Continuous data are presented as means \pm standard deviations for normally distributed variables or as median and interquartile range for non-normally distributed variables. Categorical data are presented as absolute values and frequencies (\%). Comparative analyses for the MBP and MMP groups were performed using Fisher's exact or Chi-square test for categorical variables and Student's t-test or Mann-Whitney U test for continuous variables, as appropriate. $\mathrm{P}$ values $<0.05$ were considered statistically significant. All statistical analyses were performed using IBM SPSS 20 (IBM, USA). We used Cox proportional hazard models to analyze the competing risk data and Fine and Gray cumulative incidence function-based proportional hazard competing risk regression model to analyze survival data.[11]

\section{Results}

Between January 2010 and February 2020, 556 female patients underwent mitral valve surgery at our center, of whom $355(64 \%)$ were subjected to MVR and were included in the study, and $201(36 \%)$ were subjected to mitral valve repair. Among those subjected to MVR, $174(49 \%)$ received MBP (Group I) and $181(51 \%)$ received MMP (Group II). In the overall included population, 266 (75\%) patients were in childbearing period [Group I: 134(77\%); Group II: 132 (73\%)]. Moreover, 263 (74\%) patients had rheumatic mitral valve disease [243 (74\%) severe mitral regurgitation grade ([?]V); $220(62 \%)$ annular dilatation], and 128 (36\%) had AF.

Comparison of preoperative patient demographics, socioeconomic status, mitral valve pathology, and echocardiographic data showed no statistically significant differences between groups (Table 1). Operative parameters were also not significantly different between groups, except cardiopulmonary bypass time that was significantly shorter in Group I than in Group II $(p=0.0001$; Table 2). Moreover, the postoperative ICU and clinical follow-up course were better and hospital and ICU stays were significantly shorter in Group I than in Group II $(p<0.0001)$ (Table 3), probably because patients in Group II needed to wait for the target therapeutic international normalized ratio (INR) (range 2.5-3 folds the normal value) and had more postoperative complications than those than those in Group I.

Postoperative NYHA-class status was much improved in Group I compared to that in Group II $(p$ $=0.04)$. Notably, the frequency of mitral valve re-replacement was higher in Group II than in Group I (3.7\% vs. $0.6 \% ; p=0.02)$.

Postoperative complications, including wound infection, pericardial tamponade, AF, pneumothorax, pneumonia, and ARF, showed no significant differences between groups. Immediate operative death was only seen in $0.6 \%$ of the patients in Group II. After 10years of follow-up, the postoperative transvalvular pressure gradient was significantly lower and the vena contracta was significantly wider in Group I than in Group II $(p<0.0001$ and $p=0.006$, respectively).

At 30days postoperatively, $3(0.8 \%)$ patients in the overall population died [one in Group I (0.6\%) and two in Group II (1.2\%)]. The most common complication at 30 days after surgery was AF [68 patients (19\%)].Moreover, $36(10 \%)$ patients experienced pneumonia, 5 (1.4\%) wound infection, 28 (7.9\%) pericardial tamponade, $13(3.7 \%)$ pneumothorax, 9 (2.5\%) pleural effusion, and 14 (3.9\%) stroke. Additionally, 34 (9.6\%) patients had ARF, with only $10(2.8 \%)$ requiring temporary hemodialysis, while $29(8.2 \%)$ patients suffered from A-V block grade III, and $27(7.6 \%)$ had pacemaker implantation. Re-exploration for postoperative bleeding occurred in $22(6.2 \%)$ patients and was significantly more frequent among Group II [18 (10\%)] than in Group I $[4(2.4 \%)]$ patients $(p<0.0001)$. Abortion occurred in $32(9 \%)$ women in child-bearing period and was significantly more frequent among Group II [27 (15\%)] than in Group I [5 (3\%)] patients $(p=0.0001)$. Anticoagulant complication-free pregnancy occurred in $242(68.2 \%)$ women in child-bearing period, and the rate was significantly higher in Group I [141 patients (81\%)] than in Group II [101 (56\%)] $(p<0.0001$; Table $4)$. 
Oral anticoagulants such as coumadin were available at all times for all patients, but compliance to these drugs was $81 \%$. The INR of Group II patient was in the therapeutic target most of the times. Moreover, 5 out of 7 patients in this group who had mitral valve re-replacement due to poor oral anticoagulant compliance or failure of coumadin treatment to reach the INR therapeutic target in pregnant woman resulting in lifethreatening mechanical valve thrombosis in a pregnant woman who received MMP $(5+-2)$ years before pregnancy. However, all a majority of them were successfully treated with MBP re-replacement but had a significant risk of miscarriage. In contrast, there was only one case for mitral valve re-replacement in Group I due to structural valve deterioration. Additionally, 18 (10\%) Group II patients aborted due to teratogenicity related to coumadin, representing about $67 \%(18 / 27)$ of all abortion cases in this group.

The Kaplan-Meier curves of postoperative complications and survival rate over the 10-year follow-up period are presented in Figure 1. The survival rate was significantly higher in Group I than in Group II ( $88 \%$ vs $63 \% p<0.0001)$. The $95 \%$ confidence interval of Cox hazards survival regression ratio was significantly different between groups [0.1926 (0.0759-0.4889), $p=0.0001]$, whereas the adjusted $95 \%$ confidence interval for preoperative variables (age, logistic EuroScore-I, mitral regurgitation grade 4) was not $[0.5581(0.3254-0.9581), p=0.059670]$.

\section{Discussion}

This single-center study delineates the safety and efficacy of two types of mitral valve prostheses. The event rate of mitral valve re-replacement was high after MMP, possibly due to poor compliance to the oral anticoagulant treatment, owing to the young women's desire to become pregnant. Furthermore, our study confirmed the remarkably high success rate of MBP in young women, whereas MMP was associated with an increased risk of postoperative bleeding. Since both prostheses types have advantages and disadvantages, specific patient characteristics must be considered when choosing the appropriate type. $[12,13]$

A recent report demonstrated that MBP has superior antithrombotic properties and longer durability, whereas MMP is associated with thromboembolism and bleeding events. [5,14] Consistently, our study showed that oral anticoagulant use among young women with MMP is associated with a high risk of postoperative bleeding and abortion, and increased frequency of pregnancy-related complications. Moreover, there was a considerable survival benefit for young women with MBP.

Kaplan-Meier analysis of the long-term survival at 10 years of follow-up after MVR demonstrated a significantly higher survival rate with MBP (88\%) than with MMP (63\%), despite survival being equivalent between groups for the first three years of follow-up. Subsequent competing risk regression analyses indicated a significant survival difference between groups; however, adjustment for preoperative baseline variables showed no significant difference between groups.

Specific patient characteristics, including child-bearing period, frequency of medical visits and blood tests, as well as the possibility of anticoagulant-related thrombotic and bleeding events and teratogenicity, particularly in pregnant women, influenced the choice of mitral valve prosthesis type in young women. The rate of comorbidities, such as AF, renal failure, obesity, diabetes mellitus, and operative factors were not significantly different between groups. In the future, MBP implantation in young women will benefit from the trans-catheter valve-in-valve technique in cases of structural valve deterioration, thus decreasing the reoperation risk. Furthermore, newer MBPs with longer durability may also be more attractive for young women from the perspective of both the patient and medical care.

Our results match those of the Society of Thoracic Surgeons database report from 2000 to 2007, indicating that the age of women receiving MBP has been significantly reduced, and that the rate of MMP implantation has decreased from $68 \%$ to $37 \%$ among young women.[15 ] Woo et al reported that young age is not a risk factor for the structural deterioration of MBP, which agrees with our results. Moreover, the authors showed that the freedom from reoperation rates at 10, 15, and 20 years after new MBP due to structural valve deterioration were 91,76 , and $50 \%$, respectively.[16]

Previous studies have shown that only $62 \%$ of young women on oral anticoagulants who re- 
ceive MMP are within an acceptable INR range.[12,17,18]

Applegate et al reported that the structural deterioration of MBP is unclear and possibly a result of calcium and lipids accumulation over the valve surface, and suggested that a complete saline rinse of the MBP more than once before surgery leads to a considerable decrease in structural deterioration frequency.[19] Although older-generation MBPs undoubtedly had limited durability, newer MBPs have excellent long-term durability and performance for $>25$ years.[15]

Our results agree with those by Walfisch et al who reported that the use of vitamin $\mathrm{K}$ antagonists, such as coumadin, even at doses $<5 \mathrm{mg}$ during pregnancy holds a very high possibility of serious risks to the fetus, especially during the first trimester or at term. However, one of the most common international protocols suggested the substitution of coumadin by heparin between the 6th and 12th gestational week to reduce the risk of teratogenicity. Nevertheless, since coumadin has a long half-life, with a terminal elimination half-life of one week, heparin substitution starting at 6 gestational weeks is too late to avoid teratogenicity.[20]

In our study, abortion was significantly higher in the MMP (15\%) than in the MBP group (3\%). Moreover, the rate of freedom from anticoagulant-related complications among women in child-bearing period was significantly higher in the latter ( $81 \%$ versus $56 \%)$.

The impulse use of MBP in young female patients at childbearing period is explained by the classic surgical recommendation of life-time anticoagulants' use after MMP, the lower risk of reoperation by using newgeneration MBPs, the future possibility of valve-in-valve technique, as well as by the patients' decision to refusethe activity constraints associated with anticoagulants. 7,21

Our study is limited by its non-randomized prospective design and small sample size. Thus, our results should be verified in future studies including a larger prospective randomized study sample.

\section{Conclusions}

Our data confirm that using MBP in young women who wish to become pregnant is safe, decreases complications, and improves survival. The recorded 10-year survival rate was higher with MBP than with MMP in these patients. Therefore, valve selection in young women is important for the patient's survival.

\section{Conflicts of interest}

There are no conflicts of interest.

\section{References}

1. Frater RW, Furlong P, Cosgrove DM, Okies JE, Colburn LQ, Katz AS, Lowe NL, Ryba EA. Long-term durability and patient functional status of the Carpentier-Edwards Perimount pericardial bioprosthesis in the aortic position. J Heart Valve Dis 1998;7:48-53.

2. Kulik A, Bedard P, Lam BK, Rubens FD, Hendry PJ, Masters RG, Mesana TG, Ruel M.Mechanical versus bioprosthetic valve replacement in middle-aged patients. Eur J Cardiothorac Surg 2006; 30:485-491.

3. Chikwe J, Chiang YP, Egorova NN, Itagaki S, Adams DH. Survival and outcomes following bioprosthetic vs mechanical mitral valve replacement in patients aged 50 to 69 years. JAMA2015; 313:1435-1442.

4. Nishimura RA, Otto CM, Bonow RO, Carabello BA, Erwin JP 3rd, Guyton RA, O'Gara PT, Ruiz CE, Skubas NJ, Sorajja P, Sundt TM 3rd, Thomas JD; American College of Cardiology/American Heart Association Task Force on Practice Guidelines. 2014 AHA/ACC guideline for the management of patients with valvular heart disease: executive summary: a report of the American College of Cardiology/American Heart Association Task Force on Practice Guidelines. Circulation 2014; 129:2440-2492.

5. Wang Y, Chen S, Shi J, Li G, Dong N. Mid- to long-term outcome comparison of the Medtronic Hancock II and bi-leaflet mechanical aortic valve replacement in patients younger than 60 years of age: a propensitymatched analysis. Interact CardiovascThorac Surg 2015; 22:1-7. 
6. Cunanan CM, Cabiling CM, Dinh TT, Shen SH, Tran-Hata P, Rutledge JH 3rd, Fishbein MC. Tissue characterization and calcification potential of commercial bioprosthetic heart valves. Ann Thorac Surg 2001; 71:417-421.

7. Kaneko T, Aranki S, Javed Q, McGurk S, Shekar P, Davidson M, Cohn L. Mechanical versus bioprosthetic mitral valve replacement in patients $<65$ years old. J Thorac Cardiovasc Surg 2014; 147:117-126.

8. Kyriacou DN, Lewis RJ. Confounding by indication in clinical research. JAMA. 2016; 316:1818-1819.

9. Sordelli C, Severino S, Ascione L, Coppolino P, Caso P. Echocardiographic assessment of heart valve prostheses. J Cardiovasc Echogr2014; 24:103-113.

10. Castillo JG, Solis J, Gonzalez-Pinto A, Adams DH. Surgical echocardiography of the mitral valve. Rev Esp Cardiol 2011; 64:1169-1181.

11. Fine JP, Gray RJ. A proportional hazards model for the subdistribution of a competing risk. J Am Stat Assoc 1999;94:496-509.

12. Tillquist MN, Maddox TM. Cardiac crossroads: deciding between mechanical or bioprosthetic heart valve replacement. Patient Prefer Adherence 2011; 5:91-99.

13. Fino C, Iacovoni A, Pibarot P, Pepper JR, Ferrero P, Merlo M, Galletti L, Caputo M, Ferrazzi P, Anagnostopoulos C, Cugola D, Senni M, Bellavia D, Magne J. Exercise hemodynamic and functional capacity after mitral valve replacement in patients with ischemic mitral regurgitation: a comparison of mechanical versus biological prostheses. Circ Heart Fail 2018;11:e004056.

14. Iung B, Rodes-Cabau J. The optimal management of anti-thrombotic therapy after valve replacement: certainties and uncertainties. Eur Heart J 2014; 35:2942-2949.

15. Gammie JS, Sheng S, Griffith BP, Peterson ED, Rankin JS, O'Brien SM, Brown JM. Trends in mitral valve surgery in the United States: results from the Society of Thoracic Surgeons Adult Cardiac Database. Ann Thorac Surg 2009; 87:1431-1439.

16. Woo YJ, Greene CL. Prosthetic valve choice in middle-aged patients:guidelines and other guiding principles. Eur J Cardiothorac Surg 2016; 49:1468-1469.

17. Rahimtoola SH. Choice of prosthetic heart valve in adults. Am Coll Cardiol 2010; 55:2413-2426.

18. Hui C, Lili M, Libin C, Rui Z, Fang G, Ling G, Jianping Z. Changes in coagulation and hemodynamics during pregnancy: a prospective longitudinal study of 58 cases. Arch Gynecol Obstet 2012; 285:1231-1236.

19. Applegate PM, Boyd WD, Applegate li RL, Liu H. Is it the time to reconsider the choice of valves for cardiac surgery: mechanical or bioprosthetic? J Biomed Res 2017; 31:373-376.

20. Walfisch A, Koren G. The "warfarin window" in pregnancy: the importance of half-life. J Obstet Gynaecol Can 2010; 32:988-989.

21. Batra J, Itagaki S, Egorova NN, Chikwe J. Outcomes and long-term effects of pregnancy in women with biologic and mechanical valve prostheses. Am J Cardiol 2018;122:1738-1744.

Table 1: Preoperative baseline characteristics

\begin{tabular}{llll}
\hline & Mitral bioprosthesis & $\begin{array}{l}\text { Mitral mechanical } \\
\text { prosthesis } \mathrm{N}=181\end{array}$ & P value \\
\hline Age (years) & $47.6 \pm 9.9$ & $46.5 \pm 10$ & 0.30 \\
Childbearing period & $134(77 \%)$ & $132(73 \%)$ & 0.39 \\
Body & $26.2 \pm 1.6$ & $26.5 \pm 1.8$ & 0.098 \\
mass index $\left(\mathrm{Kg} / \mathrm{m}^{2}\right)$ & & Socioeconomic status & Socioeconomic status \\
Socioeconomic status & Socioeconomic status & &
\end{tabular}




\begin{tabular}{|c|c|c|c|}
\hline & $\begin{array}{l}\text { Mitral bioprosthesis } \\
\mathrm{N}=174\end{array}$ & $\begin{array}{l}\text { Mitral mechanical } \\
\text { prosthesis } \mathrm{N}=181\end{array}$ & $\mathrm{P}$ value \\
\hline Poor & $66(38 \%)$ & $65(36 \%)$ & 0.69 \\
\hline Middle & $75(43 \%)$ & $85(47 \%)$ & 0.45 \\
\hline Rich & $33(19 \%)$ & $31(17 \%)$ & 0.62 \\
\hline Hypertension (\%) & $77(44 \%)$ & $76(42 \%)$ & 0.70 \\
\hline Diabetes mellitus (\%) & $47(27 \%)$ & $45(24.8 \%)$ & 0.64 \\
\hline Obesity (\%) & $44(25.3 \%)$ & $46(25.4 \%)$ & 0.93 \\
\hline $\begin{array}{l}\text { Family history } \\
\text { of cardiac surgery (\%) }\end{array}$ & $19(11 \%)$ & $27(15 \%)$ & 0.26 \\
\hline $\begin{array}{l}\text { Past history of cardiol- } \\
\text { ogy intervention }(\%)\end{array}$ & $9(5 \%)$ & $11(6 \%)$ & 0.68 \\
\hline $\begin{array}{l}\text { History of previous } \\
\text { mitral valve repair }(\%)\end{array}$ & $5(3 \%)$ & $7(3.7 \%)$ & 0.61 \\
\hline Renal failure (\%) & $6(3.6 \%)$ & $6(3.3 \%)$ & 0.87 \\
\hline $\begin{array}{l}\text { Cerebrovascular acci- } \\
\text { dent } \\
(\%)\end{array}$ & $4(2.4 \%)$ & $3(1.7 \%)$ & 0.83 \\
\hline Chronic lung disease (\%) & $25(14.4 \%)$ & $28(15.5 \%)$ & 0.75 \\
\hline $\begin{array}{l}\text { Peripheral vascular } \\
\text { disease }(\%)\end{array}$ & $26(15 \%)$ & $29(16 \%)$ & 0.79 \\
\hline Atrial fibrillation (\%) & $61(35 \%)$ & $67(37 \%)$ & 0.69 \\
\hline EuroScore & $5.6 \pm 1.4$ & $5.9 \pm 2.3$ & 0.14 \\
\hline $\begin{array}{l}\text { New York Heart } \\
\text { Association class }\end{array}$ & $3.86 \pm 0.34$ & $3.88 \pm 0.31$ & 0.56 \\
\hline $\begin{array}{l}\text { Echocardiographic data } \\
\text { Mitral valve pathology }\end{array}$ & Echocardiographic data & Echocardiographic data & Echocardiographic data \\
\hline Mitral stenosis (\%) & $57(32.8 \%)$ & $59(32.6 \%)$ & 0.97 \\
\hline $\begin{array}{l}\text { Severe mitral } \\
\text { regurgitation (> grade } \\
\text { 4) }(\%)\end{array}$ & $118(68 \%)$ & $125(69 \%)$ & 0.84 \\
\hline Rheumatic (\%) & $127(73 \%)$ & $136(75.1 \%)$ & 0.67 \\
\hline Degenerative (\%) & $31(18 \%)$ & $29(16 \%)$ & 0.62 \\
\hline Endocarditis (\%) & $16(9 \%)$ & $14(7.7 \%)$ & 0.73 \\
\hline Ejection fraction $(\%)$ & $50 \pm 10$ & $52 \pm 12$ & 0.09 \\
\hline $\begin{array}{l}\text { Left ventricular end } \\
\text { diastolic diameter }(\mathrm{cm})\end{array}$ & $5.1 \pm 0.7$ & $5 \pm 0.5$ & 0.12 \\
\hline $\begin{array}{l}\text { Left ventricular end } \\
\text { systolic diameter }(\mathrm{cm})\end{array}$ & $3.6 \pm 0.4$ & $3.7 \pm 0.6$ & 0.07 \\
\hline Left atrium $(\mathrm{cm})$ & $4.3 \pm 0.5$ & $4.4 \pm 0.7$ & 0.12 \\
\hline Right atrium $(\mathrm{cm})$ & $4.6(3.9-5.2)$ & $4.8(4-5.5)$ & 0.32 \\
\hline $\begin{array}{l}\text { Pulmonary artery } \\
\text { pressure }(\mathrm{mmHg})\end{array}$ & $43 \pm 7$ & $44 \pm 9$ & 0.24 \\
\hline Annular dilatation & $106(61.1 \%)$ & $114(63 \%)$ & 0.71 \\
\hline $\begin{array}{l}\text { Annular or } \\
\text { subvalvular calcification }\end{array}$ & $49(28 \%)$ & $58(32 \%)$ & 0.41 \\
\hline
\end{tabular}

Values are presented as number of patients and percentage, means and standard deviation, or median and interquartile range.EuroScore: European System for Cardiac Operative Risk Evaluation (low risk: < 2 points, moderate risk: $3-5$ points, high risk: ¿ 6 points) 
Table 2: Operative data

\begin{tabular}{llll}
\hline & $\begin{array}{l}\text { Mitral bioprosthesis } \\
\mathrm{N}=174\end{array}$ & $\begin{array}{l}\text { Mitral mechanical } \\
\text { prostheses N =181 }\end{array}$ & P value \\
\hline $\begin{array}{l}\text { Cardiopulmonary } \\
\text { bypass time (min) }\end{array}$ & $105 \pm 15.7$ & $115 \pm 18.2$ & 0.0001 \\
$\begin{array}{l}\text { Aortic } \\
\text { cross-clamping time }\end{array}$ & $73 \pm 12$ & $75 \pm 13$ & 0.13 \\
$\begin{array}{l}\text { min) } \\
\text { Mitral valve size }\end{array}$ & Mitral valve size & Mitral valve size & Mitral valve size \\
$25 \mathrm{~mm}(\%)$ & $24(14 \%)$ & $27(15 \%)$ & 0.79 \\
$27 \mathrm{~mm}(\%)$ & $79(45 \%)$ & $89(49 \%)$ & 0.45 \\
$29 \mathrm{~mm}(\%)$ & $66(38 \%)$ & $58(32 \%)$ & 0.24 \\
$31 \mathrm{~mm}(\%)$ & $5(3 \%)$ & $7(4 \%)$ & 0.61 \\
$\begin{array}{l}\text { Concomitant atrial } \\
\text { fibrillation ablation (\%) }\end{array}$ & $61(35 \%)$ & $67(37 \%)$ & 0.69 \\
$\begin{array}{l}\text { Tricuspid valve repair } \\
\text { (\%) }\end{array}$ & $54(31 \%)$ & $53(29 \%)$ & 0.68 \\
$\begin{array}{l}\text { Tricuspid } \\
\text { valve replacement }(\%)\end{array}$ & $9(5 \%)$ & $13(7.1 \%)$ & 0.43 \\
\hline
\end{tabular}

Values are presented as number of patients and percentage or means and standard deviation.

Table 3: Postoperative follow-up data

\begin{tabular}{|c|c|c|c|}
\hline & $\begin{array}{l}\text { Mitral bioprosthesis } \\
\mathrm{N}=174\end{array}$ & $\begin{array}{l}\text { Mitral mechanical } \\
\text { prostheses } N=181\end{array}$ & $\mathrm{P}$ value \\
\hline $\begin{array}{l}\text { Ventilation } \\
\text { time (hours) }\end{array}$ & $13.8(9-18)$ & $14.3(8-20)$ & 0.17 \\
\hline $\begin{array}{l}\text { Intensive care } \\
\text { unit stay (hours) }\end{array}$ & $38.2 \pm 15.7$ & $46 \pm 17$ & $<0.0001$ \\
\hline Hospital stay (hours) & $11.7 \pm 2$ & $15.5 \pm 2.6$ & $<0.0001$ \\
\hline $\begin{array}{l}\text { New York Heart } \\
\text { Association class }\end{array}$ & $1.1 \pm 0.4$ & $1.2 \pm 0.5$ & 0.04 \\
\hline Wound infection (\%) & $2(1.2 \%)$ & $3(1.7 \%)$ & 0.82 \\
\hline $\begin{array}{l}\text { Pericardial tamponade } \\
(\%)\end{array}$ & $11(6.5 \%)$ & $17(9.3 \%)$ & 0.33 \\
\hline $\begin{array}{l}\text { Atrio-ventricular block } \\
\text { grade III (\%) }\end{array}$ & $13(7.3 \%)$ & $16(8.8 \%)$ & 0.61 \\
\hline Atrial fibrillation (\%) & $37(21 \%)$ & $31(17 \%)$ & 0.34 \\
\hline Pneumonia (\%) & $17(9.5 \%)$ & $19(10.5 \%)$ & 0.82 \\
\hline Pneumothorax (\%) & $4(2.4 \%)$ & $9(5 \%)$ & 0.27 \\
\hline Pleural effusion (\%) & $6(3.6 \%)$ & $3(1.7 \%)$ & 0.19 \\
\hline $\begin{array}{l}\text { Pacemaker } \\
\text { implantation (\%) }\end{array}$ & $13(7.3 \%)$ & $14(7.7 \%)$ & 0.94 \\
\hline Acute renal failure (\%) & $16(9 \%)$ & $18(10 \%)$ & 0.75 \\
\hline Temporary dialysis (\%) & $3(2 \%)$ & $7(3.7 \%)$ & 0.27 \\
\hline Stroke $(\%)$ & $6(3.6 \%)$ & $8(4.4 \%)$ & 0.66 \\
\hline
\end{tabular}




\begin{tabular}{|c|c|c|c|}
\hline & $\begin{array}{l}\text { Mitral bioprosthesis } \\
\mathrm{N}=174\end{array}$ & $\begin{array}{l}\text { Mitral mechanical } \\
\text { prostheses } \mathrm{N}=181\end{array}$ & $\mathrm{P}$ value \\
\hline $\begin{array}{l}\text { Re-exploration for } \\
\text { postoperative bleeding } \\
\text { (\%) }\end{array}$ & $4(2.4 \%)$ & $18(10 \%)$ & $<0.0001$ \\
\hline $\begin{array}{l}\text { Immediate } \\
\text { operative death }\end{array}$ & 0 & $1(0.6 \%)$ & \\
\hline 30-day death $(\%)$ & $1(0.6 \%)$ & $2(1.2 \%)$ & 0.29 \\
\hline 30-day cardiac death (\%) & 0 & 0 & \\
\hline $\begin{array}{l}\text { 30-day non-cardiac death } \\
(\%)\end{array}$ & $1(0.6 \%)$ & $2(1.2 \%)$ & 0.29 \\
\hline 10-year death $(\%)$ & $6(3.6 \%)$ & $18(10 \%)$ & 0.01 \\
\hline 10 year cardiac death & $2(1.2 \%)$ & $12(6.7 \%)$ & 0.007 \\
\hline 10-year non-cardiac death & $4(2.4 \%)$ & $6(3.3 \%)$ & 0.58 \\
\hline Mitral re-replacement & $1(0.6 \%)$ & $7(3.7 \%)$ & 0.02 \\
\hline Abortion & $5(3 \%)$ & $27(15 \%)$ & 0.0001 \\
\hline $\begin{array}{l}\text { Abortion due } \\
\text { to teratogenicity related } \\
\text { to coumadin }\end{array}$ & - & $18(10 \%)$ & \\
\hline $\begin{array}{l}\text { Abortion due } \\
\text { to teratogenicity not } \\
\text { related to coumadin }\end{array}$ & $4(2.4 \%)$ & $5(3 \%)$ & 0.73 \\
\hline $\begin{array}{l}\text { Abortion due to other } \\
\text { causes (infection, } \\
\text { physical problem, uterine } \\
\text { anomalies) }\end{array}$ & $1(0.6 \%)$ & $4(2 \%)$ & 0.25 \\
\hline $\begin{array}{l}\text { Pregnancy free } \\
\text { of anticoagulant } \\
\text { complications }\end{array}$ & $141(81 \%)$ & $101(56 \%)$ & $<0.0001$ \\
\hline Echocardiographic data & & & \\
\hline Ejection fraction $(\%)$ & $53 \pm 11$ & $52 \pm 13$ & 0.44 \\
\hline $\begin{array}{l}\text { Left ventricular end } \\
\text { diastolic diameter }(\mathrm{cm})\end{array}$ & $5.1 \pm 0.3$ & $5 \pm 0.6$ & 0.05 \\
\hline $\begin{array}{l}\text { Left ventricular end } \\
\text { systolic diameter }(\mathrm{cm})\end{array}$ & $3.7 \pm 0.6$ & $3.8 \pm 0.5$ & 0.08 \\
\hline Left atrium $(\mathrm{cm})$ & $4.3 \pm 0.4$ & $4.2 \pm 0.6$ & 0.07 \\
\hline Right atrium $(\mathrm{cm})$ & $4.7(4.2-5.2)$ & $4.8(4.2-5.4)$ & 0.09 \\
\hline $\begin{array}{l}\text { Transprosthetic pressure } \\
\text { gradient }(\mathrm{mmHg})\end{array}$ & $7 \pm 3$ & $15 \pm 4$ & $<0.0001$ \\
\hline $\begin{array}{l}\text { Pulmonary artery } \\
\text { pressure }(\mathrm{mmHg})\end{array}$ & $43 \pm 5$ & $42 \pm 6$ & 0.08 \\
\hline $\begin{array}{l}\text { Width of the vena } \\
\text { contracta }(\mathrm{cm})\end{array}$ & $0.67 \pm 0.08$ & $0.64 \pm 0.12$ & 0.006 \\
\hline
\end{tabular}

Values are presented as number of patients and percentage, means and standard deviation, or median and interquartile range.

Table 4: Ten-year outcomes 


\begin{tabular}{|c|c|c|c|c|}
\hline & $\begin{array}{l}\text { Mitral bioprosthesis } \\
N=174\end{array}$ & $\begin{array}{l}\text { Mitral mechanical } \\
\text { prostheses } \mathrm{N}=181\end{array}$ & OR $(95 \%$ CI $)$ & AOR $(95 \%$ CI $)$ \\
\hline $\begin{array}{l}\text { Re- } \\
\text { exploration for- } \\
\text { postopera- } \\
\text { tive bleeding } \\
(\%)\end{array}$ & $4(3.2 \%)$ & $18(10 \%)$ & $\begin{array}{l}0.2052 \\
(0.1047-0.4023)\end{array}$ & $\begin{array}{l}0.1847 \\
(0.0838-0.3902)\end{array}$ \\
\hline 10-year death $(\%)$ & $6(3.5 \%)$ & $18(10 \%)$ & $\begin{array}{l}0.3234 \\
(0.1252-0.8352)\end{array}$ & $\begin{array}{l}0.2426(0.0808- \\
0.7350)\end{array}$ \\
\hline Re-operation (\%) & $1(0.6 \%)$ & $7(3.7 \%)$ & $\begin{array}{l}0.1437 \\
(0.0175-1.1802)\end{array}$ & $\begin{array}{l}0.1078(0.0113- \\
1.039)\end{array}$ \\
\hline Abortion & $5(3 \%)$ & $27(15 \%)$ & $\begin{array}{l}0.1687 \\
(0.0634-0.4491)\end{array}$ & $\begin{array}{l}0.0702(0.0209- \\
0.2425)\end{array}$ \\
\hline $\begin{array}{l}\text { Pregnancy free } \\
\text { of anticoagulant } \\
\text { complications }\end{array}$ & $141(81 \%)$ & $101(56 \%)$ & $\begin{array}{l}3.3843 \\
(2.0957-5.4654)\end{array}$ & $\begin{array}{l}1.4079 \\
(0.6916-2.9513)\end{array}$ \\
\hline $\begin{array}{l}\text { Pacemaker } \\
\text { implantation (\%) }\end{array}$ & $13(7.3 \%)$ & $14(7.5 \%)$ & $\begin{array}{l}0.9632 \\
(0.4392-2.1124)\end{array}$ & $\begin{array}{l}1.5411 \\
(0.7686-3.0947)\end{array}$ \\
\hline $\begin{array}{l}\text { Acute renal } \\
\text { failure }(\%)\end{array}$ & $16(9 \%)$ & $18(10 \%)$ & $\begin{array}{l}0.8624 \\
(0.4253-1.7491)\end{array}$ & $\begin{array}{l}0.3277 \\
(0.1263-0.8133)\end{array}$ \\
\hline $\begin{array}{l}\text { Temporary } \\
\text { dialysis (\%) }\end{array}$ & $3(2 \%)$ & $7(4 \%)$ & $\begin{array}{l}0.4361 \\
(0.1109-1.7143)\end{array}$ & $\begin{array}{l}0.1657(0.0329- \\
0.7971)\end{array}$ \\
\hline Stroke (\%) & $6(3.5 \%)$ & $8(4.4 \%)$ & $\begin{array}{l}0.7723 \\
(0.2624-2.2733)\end{array}$ & $\begin{array}{l}0.2935 \\
(0.0777-1.0571)\end{array}$ \\
\hline 30-day death (\%) & $1(0.6 \%)$ & $2(1.1 \%)$ & $\begin{array}{l}0.5173 \\
(0.0465-5.7576)\end{array}$ & $\begin{array}{l}0.3078 \\
(0.0239-4.0534)\end{array}$ \\
\hline $\begin{array}{l}\text { Wound infection } \\
(\%)\end{array}$ & $2(1.4 \%)$ & $3(1.7 \%)$ & $\begin{array}{l}0.6899 \\
(0.1139-4.1799)\end{array}$ & $\begin{array}{l}0.3415 \\
(0.0501-2.4870)\end{array}$ \\
\hline $\begin{array}{l}\text { Pericardial tam- } \\
\text { ponade } \\
(\%)\end{array}$ & $11(6.5 \%)$ & $17(9.3 \%)$ & $\begin{array}{l}0.6510 \\
(0.2958-1.4328)\end{array}$ & $\begin{array}{l}0.4687 \\
(0.1914-1.1391)\end{array}$ \\
\hline $\begin{array}{l}\text { Atrio- } \\
\text { ventricular block } \\
\text { grade III }(\%)\end{array}$ & $13(7.5 \%)$ & $16(9 \%)$ & $\begin{array}{l}0.8327 \\
(0.3881-1.7865)\end{array}$ & $\begin{array}{l}0.4846 \\
(0.1995-1.1577)\end{array}$ \\
\hline $\begin{array}{l}\text { Atrial fibrilla- } \\
\text { tion (\%) }\end{array}$ & $37(21 \%)$ & $31(17 \%)$ & $\begin{array}{l}1.3068 \\
(0.7688-2.2212)\end{array}$ & $\begin{array}{l}0.8886 \\
(0.4882-1.6215)\end{array}$ \\
\hline Pneumonia (\%) & $17(9.5 \%)$ & $19(10.5 \%)$ & $\begin{array}{l}0.9232 \\
(0.4630-1.8410)\end{array}$ & $\begin{array}{l}0.7663 \\
(0.3602-1.6385)\end{array}$ \\
\hline $\begin{array}{l}\text { Pneumothorax } \\
\text { (\%) }\end{array}$ & $4(2.3 \%)$ & $9(4.7 \%)$ & $\begin{array}{l}0.4497 \\
(0.1359-1.4881)\end{array}$ & $\begin{array}{l}0.4497 \\
(0.0906-1.8750)\end{array}$ \\
\hline $\begin{array}{l}\text { Pleural effusion } \\
(\%)\end{array}$ & $6(3.5 \%)$ & $3(1.4 \%)$ & $\begin{array}{l}2.1190 \\
(0.5216-8.6093)\end{array}$ & $\begin{array}{l}2.1614 \\
(0.4940-9.2550)\end{array}$ \\
\hline
\end{tabular}

Data are presented as number of patients and percentage.

AOR: adjusted odds ratio for preoperative age, logistic EuroScore-I, and mitral regurgitation grade 4; CI: confidence interval; OR: odds ratio calculated by logistic regression

Figure 1: Kaplan-Meier curve for the long-term survival after mitral bioprosthesis versus mitral mechanical prosthesis 


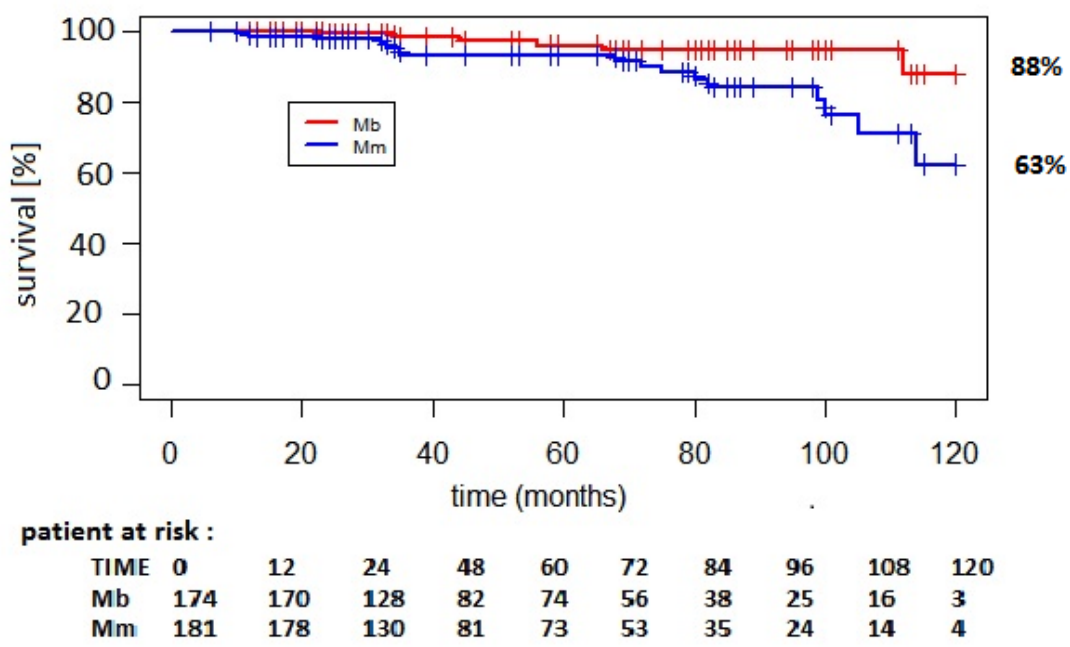

